\title{
Secondary, Tertiary and Quaternary Cytoreductive Surgery In Recurrent Epithelial Ovarian Cancer
}

\section{Rekküren Epitelyal Over Kanserlerinde Sekonder, Tersiyer ve Kuarterner Sitoredüktif Cerrahisi}

\author{
Hanifi Şahin ${ }^{1}$, İbrahim Yalçın' ${ }^{1}$, Mustafa Erkan Sari ${ }^{1}$, Burak Sezgin ${ }^{2}$, Bülent Aksel ${ }^{3}$ \\ ${ }^{1}$ Sağlık Bilimleri Üniversitesi Doktor Zekai Tahir Burak Kadın Hastalığı Eğitim ve Araştırma Hastanesi, \\ Jinekololojik Onkoloji Kliniği, Ankara \\ ${ }^{2}$ Muğla Sitkı Koçman Üniversitesi Tıp Fakültesi Jinekoloji Kliniği, Muğla \\ ${ }^{3}$ Sağlık Bilimleri Üniversitesi Doktor Abdurrahman Yurtaslan Onkoloji Eğitim ve Araştırma Hastanesi, Ankara
}

Dergiye Ulaşma Tarihi: 26,12,2017 Dergiye Kabul Tarihi: 15,01,2018 Doi: 10.5505/aot.2018.43255

\section{ÖZET}

Over kanseri tedavisinde nüks hastalığın yönetimi son derece önemlidir. Çünkü rekürrens paterni over kanserinin ayrılmaz bir parçasıdır. Günümüzde nükslerin yönetiminde tekrarlayan cerrahiler ve çeşitli kemoterapi basamakları kullanılmaktadır. Sekonder, Tersiyer ve Kuarterner cerrahi girişimler nüks epitelyal over kanserlerinin ayrılmaz parçalarıdır. Günümüzde bu konuları ele alan prospektif çalışma bulunmamaktadır. Sekonder sitoredüksiyonla ilgili retrospektif çalışmalar belirli bir düzeyi yakalamıştır. Sekonder sitoredüksiyonun etkinliğinde rezidü tümör dokusu, hastalıksız sağkalım süresi ve rekürrens lokalizasyonları hasta seçiminde ve sağkalımda önemli parametreler gibi görülmektedir. Tersiyer ve kaurterner sitoredüksiyon cerrahisinin etkinliği ile ilgili yeterli çalışma yoktur. Mevcut az sayıdaki çalışmalarda rezidü tümör miktarını 0 veya $<1 \mathrm{~cm}$ ' in altına indirecek etkin bir cerrahinin yapılmasının temel nokta olduğu eğilimi vardır. Fakat her üç cerrahi yaklaşım içinde sunulan veriler son derece heterojendir. Hasta sayıları, tümörün evresi ve histolojik dağılımları, rekürrens dağılımları, sitoredüksiyon tanımları ve takip süreleri farklıdır. Bu heterojenite içinde bias kaçınılmazdır. Sonuçta cerrahlar kendince ameliyat yapabilecekleri hastaları opere etmekte ve bu hastalar salvage kemoterapisine göre iyi yaşamaktadır. Tüm çalışmalarda maksimum sitoredüksiyonun prognostik rolü vurgulansa da bu maksimalite biyolojik olarak daha iyi huylu tümörlerde elde edilmiş olabilir. Ayrıca tüm çalışmalarda ne kadar hastanın çalışma dışı bırakıldığı yazılmamaktadır. Mevcut seriler uzun zamanda toplanmakta zamanla değişen cerrahi tecrübe, teknik altyapı ve kemoterapi protokollerini içermemektedir. Çalışmaların çoğunda pre ve postoperatif dönemde hangi kemoterapi protokollerinin verildiği bilgisi üzerinde durulmamaktadır. Bir diğer dezavantaj ise yaşam kalitesi ile ilgili çalışmaların olmamasıdır. Radikal cerrahi sonrası tüm çalışmalar yaşam oranlarına odaklanmıştır. Bu derlemenin amacı rekürren epitelyal over kanserinde sekonder, tersiyer ve kuarterner sitoredüksiyon cerrahi ile ilgili yapılmış sınırlı sayıdaki çalışmayı değerlendirmek, çelışmaların eksik yönlerini ortaya koymak ve bunlar 1şığında ilerdeki çalışmalara 1 şık tutmaktır.

Anahtar Kelimeler: Overian kanser, sekonder sitoredüksiyon, Tersiyer sitoredüksiyon, Kuarterner sitoredüksiyon

ABSTRACT
Management of recurrent disease is extremely important in ovarian cancer treatment. Today, recurrent surgeries and various chemotherapy steps are used in the management of recurrences. Secondary, tertiary and quaternary surgeries are integral parts of recurrent epithelial ovarian cancers. Currently, there are no prospective studies addressing these issues. Retrospective studies about secondary cytoreduction have reached a certain level. It seems like residual tumor tissue, duration of disease-free survival and recurrence locations in the efficacy of secondary cytoreduction are important parameters in patient selection and survival. There is insufficient study about the efficiacy of tertiary and quarternary cytoreduction surgery. In the few studies available, the main point is tendency to perform an effective surgery that reduce the amount of residual tumor below 0 or $1 \mathrm{~cm}$. But the data presented in all three surgical approaches is highly heterogeneous. Patient numbers, tumor stage and histologic distribution, recurrence distributions, definition of cytoreduction and follow-up time are different. Bias is inevitable within this heterogeneity. As a result, surgeons operate patients with their own capabilities and these patients survive better than patients treated with salvage chemoterapy. Although the prognostic role of maximal 
cytoreduction is emphasized in all studies, this maximality may have been obtained from biologically more benign tumors. In addition, it does not mention how many patients are left out of work in all studies. Current series do not include surgical experience that change over time, technical infrastructure and chemotherapy protocols. Most of the studies do not focus on which chemotherapy protocols are given in the pre- and postoperative period. Also there are no studies on quality of life. All studies after radical surgery focus on survival rates.Our aim is to evaluate studies on secondary, tertiary, and quarternary cytoreductive surgery, to reveal missing aspects of studies and to contribute future studies.

Keywords: Ovarian cancer, Secondary cytoreduction, Tertiary cytoreduction, Quaternary cytoreduction

Epitelyal over kanserleri jinekoloik maligniteler içinde en çok ölümcül olanıdır. Geç bulgu vermesi ve erken evrede tanı konulmasını sağlayacak bir tarama yöntemi olmadığı için çoğunlukla \%75'i geç evrede (evre 3-4) tanı alır. Bugün için over kanserinin primer tedavisi makroskopik tümör kalmayacak şekilde agresif sitoredüksiyon ve platin bazlı kemoterapidir. Primer tedaviye yanit oranları \%70-80 oranında tam yanit alınır (1). Ama over kanseri kliniğinde rekürrens oranı takip edilen olgularda yaklaşık $\% 80$ civarındadır. Rekkürens gelişen bu malignitelerin $\% 85$ 'i hayatını kaybetmektedir (2). $\mathrm{Bu}$ yönü ile over kanseri nüks ve remisyonlarla seyreden kronik bir hastalık olduğu unutulmamalıdır. Bugün nüks over kanserlerinde optimal tedavi modalitesi tartışmalıdır. Cerrahi mi yoksa kemoterapi mi sorusunu net bir şekilde yanıt verecek randomize kontrollü prospektif bir çalışma yoktur. Literatür skonder, tersiyer ve kuarterner sitoredüksiyon cerrahileri için çelişkili sonuçlar içermektedir. İlk defa berek ve arkadaşları (3) sekonder sitoredüksiyonun sağ kalım üzerinde olumlu etkisinin olduğunu ve bununda geride birakılan rezidü tümör dokusu ile ilişkili olduğunu, ayrıca hastalıksız sağ kalım süresinin prognozda önemli olduğunu bildirmişlerdir. Chi ve arkadaşlarının (4) 157 rekürren over kanseri olgusu üzerinde yaptığı çalışmada da; optimal sekonder sitoredüksiyon yapılan ve $0,5 \mathrm{~cm}$ altında rezidü tümörü kalan ve suboptimal cerrahi yapılan yani $0,5 \mathrm{~cm}$ üzerinde rezidü tümörü kalan hastaların ortanca sağ kalım süresi sırasıyla, 56 ve 27 ay bulunmuştur. Aynı Çalışmada rekürren over kanseri vakalarında optimal sitoredüksiyonun sağ kalımı arttıracağı sonucu çıkarılmış ve bu çalışmada hastalıksız sağ kalımın(PFS) ve rekürren lokalizasyon sayısının sağ kalım ile ilişkili olduğu belirtilmişlerdir (4). 267 olguyu içeren literatürde en geniş vaka sayısı olan Harter ve arkadaşlarının (5) yürüttüğ̈̈ çok merkezli
AGO DESKTOP OVAR TRIAL isimli sekonder sitoredüksiyon çalışmasında, vakaların\%50'sinde gross rezidüel tümör kalmazken, \%26 olguda $<1 \mathrm{~cm}$ altında tümör ,\%24'ünde $>1 \mathrm{~cm}$ üzerinde rezidü tümör mevcuttu. Median sağ kalım süresi rezidü tümör olmayanlarda 45,3 ay, gross rezidü olanlarda 19 aydı. Median sağ kalım rezidüel tümörün $0-1 \mathrm{~cm}$ arasında olduğu grupta 19,6 ay , >1cm tümör bırakılan olgularda 19,7 aydı. Böylece araştırmacılar skonder sitoredüksiyonun sadece tüm gross tümörün temizlendiği grupta faydalı olabileceğini ve $0,1-1 \mathrm{~cm}$ veya $>1 \mathrm{~cm}$ gross hastalığın geride kalması durumunda anlamlı bir sağ kalım farkının olmayacağını vurgulamışlardır (5). Tian ve arkadaşlarının (6) yaptığı 123 vakalı multisenter bir MD Anderson çalışmasında $0,1-1 \mathrm{~cm}$ arasında rezidüel hastalığ 1 olan olguların dahi sekonder sitoredüksiyondan fayda gördüğünü bildirmişlerdir. Bu çalışmada 5 yıllık sağkalım tüm gross hastalığın eksize edildiği olgularda 63,2 ay $0,1-1 \mathrm{~cm}$ hastalık kalanlarda 31,1 ay ve $>1 \mathrm{~cm}$ üzerinde rezidüel hastalığı kalanlarda 15,6 ay olarak saptamışlardır (6).Skonder sitoredüksiyon ve salvage kemoterapisi alan hasta grubunu karşılaştıran bir çalışmada 217 olguya sekonder sitoredüksiyon cerrahisi uygulanmış, 572 hastaya ise salvage kemoterapi verilmiştir. Cerrahi yapılan grupta net bir şekilde fazla sağkalım elde edilmiştir. Burada skonder cerrahi için yaş, hastalıksız sağ kalım, rezidü tümör çap1 prognostik faktörler olarak belirlenmiştir. Bu kapsam da yazarlar sekonder sitoredüksiyon için hasta seçim kriterleri belirlemişlerdir. Lokalize hastalıkta hastalıksız sağ kalım (HS) ne olursa olsun skonder sitoredüksiyonun düşünülmesini; Diffüz hastalıkta ise sadece hastalıksız sağkalımın $>24$ ay olan olgularda sitoredüksiyon düşünülebileceğini belirtmişlerdir (7). Tersiyer ve kuarterner sitoredüksiyon çalışmaları primer ve skonder sitoredüksiyona göre daha zordur. Çünkü burada pek çok faktör 
analizler içerisine dahil olmaktadır. $\mathrm{Bu}$ faktörler; primer ve sekonder debulking sonucu, primer ve skonder hastalıksız sağ kalım süreleri, kullanılan kemoterapi rejimleri ve basamak sayıları, Platin bazlı kemoterapiye duyarlılık, Nüks kitlenin özellikleri (tek, multipl veya karsinomatöz olması, nüks kitlenin çapı) Ca-125 düzeyi, asit miktarı vb durumları içermektedir. Tersiyer ve kuarterner sitoredüksiyon literatürde 2000 yılından sonra gündeme gelen cerrahi yaklaşımlardır. Literatüre baktığımızda tersiyer sitoredüksiyonla ilgili 11 retroprospektif çalışma ve 1 tane reweiv, kurterner sitoredüksiyonla ilgili 3 Çalışma vardır (8-20). Gültekin ve arkadaşları (8) 20 olguyu inceledikleri bir çalışmada optimal sitoredüksiyonu $<2 \mathrm{~cm}$ tümör kabul etmişlerdir. Maksimum sitoredüksiyon (gözle görünür makroskopik tümörün kalmadığı) olgularda median sağkalım 26 ay, optimal sitoredüksiyon $(<2 \mathrm{~cm})$ yapılanlarda 15 ay, subobtimal $(>2 \mathrm{~cm}$ tümör) yapilanlarda ise 6 ay olarak saptamışlardır. Hasta sayısının azlığından dolayı multivariant analizlerde bu değerlerin ve prognositik diğer faktörlerin hiçbiri istatistiksel olarak anlamlı bulunmamıștır. Memorial sloan-kettering kanser merkezinden 2004 yilında 26 ve takiben 2010 y1lında 77 (2004 yılındaki 26 hastayı da içeren) ovarian, tubal ve primer peritoneal kanser olgusunu incelemişlerdir $(9,20)$. $\mathrm{Bu}$ çalışmada \%73 oranında rezidü hastalık bırakmayan cerrehi girişim söz konusudur. Median takip süresi 29 ay olup morbidite oran $\% 26$ mortalite oran1 $\% 0$ olarak bildirilmiştir. $\mathrm{Bu}$ çalışmada 56 komplet rezeksiyon,12 hastada rezidü tümör $<0,5 \mathrm{~cm}$ ve 9 hastada ise rezüdü tümör $>0,5 \mathrm{~cm}$ olacak şekilde cerrahi yapılmıştır. Komplet rezeksiyon yapılanlarda medyan sağ kalım 60,4 ay, $<0,5 \mathrm{~cm}$ rezüdü tümör kalanlarda 27,9 ay ve $>0,5 \mathrm{~cm}$ rezüdü tümör kalanlarda 13,6 ay olarak bildirilmiştir. $\mathrm{Bu}$ çalışmada sekonder sitoredüksiyonda olduğu gibi hastalıksız sağ kalım univariyant analizde prognositik faktör iken (hastalıksız sağkalım>12 ay ise 59,6 ay hastalıksız sağkalım $<12$ ise 30.3 ay sağ kalım bildirilmiş) multivariyant analizde tek başına rezidü tümör çapı bağımsız prognostik faktör olarak bulunmuştur. Bu iki çalışmada komplet tersiyer sitoredüksiyonun veya en azından rezüdü tümör çapının $0,5 \mathrm{~cm}$ altına düşürmenin anlamlı bir să̆ kalım avantajına yol açacağ 1 vurgulanmıştır $(9,20)$.Karam ve arkadaşları 47 olguyu içeren çalışmalarında \%64 oranında komplet tersiyer sitoredüksiyon(TSS) sağlamışlardır. Çalışma da morbidite ve mortalite oranları Memorial sloan-kettering kanser merkezinin çalışmasına benzer bir şekilde $\% 26$, mortalite $\% 0$ olarak bulunmuştur. Makroskopik rezidü tümör bırakılmayanlarda sağ kalım 24 ay, rezüdü tümör kalanlarda ise sağ kalım 16 ay olarak bildirilmiştir. $\mathrm{Bu}$ çalışmada rekürrens tümör çapı $(<5 \mathrm{~cm})$ tersiyer sitoredüksiyon kararı için bir belirteç olarak aktarılmıştır. Aynı zamanda tersiyer sitoredüksiyon cerrahisi için kötü prognositik kriteri olarak diffüz peritoneal hastalığın varlığını ortaya koymuşlardır (16). Tang ve arkadaşlarının yaptığı 159 hastayı içeren bir çalışmada 83 hastaya tersiyer sitoredüksiyon,73 hastaya da sedece kemoterapi verilmiştir. Tersiyer sitoredüksiyon yapılan grupta median sağkalım 26,9 ay, yalnız kemoterapi alan grupta ise 15,1 ay olarak bulunmuştur. Rezidü tümör kalmayan olgularda median sağ kalımm 32,9 ay, makroskopik rezidü tümör kalan olgularda median sağ kalım14,6 ay olarak bulunmuştur. $\mathrm{Bu}$ çalışmada sekonder sitoredüksiyon sonrası hastalıksız sağ kalım(PFS),mezenterik lenf nodu,ve rezidüel hastalık bağımsız prognostik faktörler olarak tanımlanmıştır. Ayrıca bu çalışmada orta ve üst abdominal hastalık ile sadece pelvik bölgede hastalık olmasının sağ kalımı etkilediğini bildirmişlerdir (pelvik tutulumda median sağ kalım: 34,6 ay; orta-üst abdominal tutulumda ise 14,6 ay olarak bulunmuştur).Multivariant analizde komplet tersiyer sitoredüksiyon yapılması durumunda abdominal tutulum bölgelerinin sağ kalımda önemli olmadığı bildirilmiştir (13). Literatürde tersiyer sitoredüksiyonla ilgili en büyük tek merkezli çalışma 135 olguyu içeren 2011 yılında Fotopoulou ve arkadaşları (11) tarafından Charite üniversitesinden yapılmıştır. Burada araştırmacilar temel vurguladıkları kriter postoperatif rezidü tümör miktarının bu konjonktürde tersiyer sitoredüksiyon cerrahisinin başarısını belirleyen en önemli etken olduğunu vurgulamışlardır. Komplet rezeksiyon dışında seröz papiller histoloji ve hastalıksız sağ kalımda üç veya daha fazla yıl intervali olan hastaların survival açısından pozitif prognoza sahip bulunmuştur. Tersiyer sitoredüksiyon yapılan hastalar ortalama 9,6 ay takip edilmiş ve median genel sağ kalım 19,1 ay bulunmuş,78 hasta takip süresi içinde 
ölmüş,52 hastada tekrar nüks gelişmiştir. Komplet tersiyer sitoredüksiyon yapilan 53 hastanın median săg kalımı 37,8 ay, $<1 \mathrm{~cm}$ rezidü tümör kalanlarda median sağ kalım 19 ay, $>1 \mathrm{~cm}$ rezidü tümör kalanlarda 6,9 ay olarak tespit edilmiştir. $\mathrm{Bu}$ çalışmada tümörün ortaüst abdomende yerleşmesi ve peritoneal karsinomatöz olması tümör rezeksiyonunu etkileyen parametreler olduğu belirtilmiştir (11).

Tersiyer sitoredüksiyon ile ilgili en geniş çalışma yine Fotopoulou ve arkadaşları (19) tarafindan 14 merkezli ve 406 olguyu içeren bir multisenter çalışmadır. Burada verilen temel mesaj komplet tümör rezeksiyonun sağlanmış olmasının ortalama sağ kalımı artıran temel etken olduğudur. Ayrıca diğer çalışmaların aksine tersiyer sitoredüksiyonun yararını açıça göstermişlerdir. Burada Tersiyer sitoredüksiyon sonrası median takip 14 ay ve total ortalama sağ kalım cerrahi sonrası 26 ay olarak tespit edilmiştir. Komplet cerrahi 224 olguya yapılmış ve bu olgularda median sağ kalım 49 ay, inkomplet cerrahi yapilan olgularda sağkalım 12 ay olarak saptanmıştır. Multivariant analizde platine resistans hastalik, sekonder sitoredüksiyon sonrası rezidü tümör ve peritoneal karsinomatozis komplet tümör rezeksiyonunda önemli etkenlerdir. Ayrıca skonder ve tersiyer sitoredüksiyon sonras1 rezidü tümör, asit, üst abdominal tutulum ve skonder sitoredüksiyon sonrası hastalıksız sağ kalım, ve platin içermeyen üç basmak kemoterapi sağ kalım üzerinde etkili olan prognostik faktörler olarak bulunmuştur. $\mathrm{Bu}$ çalışmada peritoneal karsinomatozis sağ kalım üzerinde prognositik faktör olarak bulunmamıştır. Ek olarak postoperatif kemoterapinin sağ kalım üzerinde olumlu etkisini ilk kez gösterilmiştir. Bununla ilgili genel durumu iyi ve kemoterapiyi tolere edebilen hastaların, genel durumu iyi olmayan ve kemoterapiyi tolere edemeyen hastalara göre prognozlarının daha iyi olduğu ve kemoterapiyi olumlu k1lan etkenin bu olabileceğini belirtmişlerdir. $\mathrm{Bu}$ geniş serili çalışmada 1 ay içindeki morbidite ve mortalite oranı \%25,9 ve \%3,2 olarak bulunmuştur (19). $\mathrm{Bu}$ çalışmanın prognostik kriter olarak tanımladığı asit, kemoterapi basamak sayıs1 bizim çalışmamızda prognozda herhangi bir önemi gösterilememiştir. Kusumato ve arkadaşları sekonder sitoredüksiyon sonrası 8 olguyu incelemişlerdir. Dört hastaya komplet tersiyer sitoredüksiyon yapılmış,diğer 4 hastaya da cerrahi yapılmamıştır. Cerrahi yapılan olgularda rekürrens sonrası sağ kalım 53 ay, yapilmayan olgularda 12 ay olarak bildirmişlerdir. Ayrica yazarlar hasta performasının iyi olması halinde tek veya multipl tutulumların önemi olmaksızın tersiyer sitoredüksiyonun genel ve hastalıksız sağ kalımı artırabileceğini fakat bunun net olmadığını bildirmişlerdir(18). Hızlı ve arkadaşları (12) 23 olguyu içeren bir çalışmada optimal $(<1 \mathrm{~cm})$ tersiyer sitoredüksiyon cerrahisi yapılan hastalarda hastalıksız sağ kalım süresini yapılamayanlara göre univariant analizde daha anlamlı bulmuşlardır. Tresiyer sitoredüksiyona etki eden klinikopatolojik bir faktör tanımlamamışlardır. Arvas ve arkadaşları (17) 53 olguyu içeren multisenter çalışmalarında primer,skonder ve tersiyer sitoredüksiyon sonrası rezidü tümör çapının sağ kalım üzerinde etkili olduğunu vurgulamışlardır. TSS sonrası $<0,5 \mathrm{~cm}$ altında rezidü tümör olanlarda ortalama sağ kalım 40 ay , $>0,5 \mathrm{~cm}$ üzerinde olanlarda 18 ay olarak tespit edilmiştir. Optimal $\operatorname{TSS}(<0,5 \mathrm{~cm})$ belirleyen faktörler 2.nükse kadar olan hastalıksız sağ kalım, SSR sonraki hastalıksız sağ kalım, rekküren tümör çapı takip sırasında hastalığın son durumudur. Ayrica optimal primer sitoredüsiyon, TSS ve önceki Ca-125 düzeyleri univariant analizde bağımsız prognositik faktörler olarak bildirilmiştir.

Kuarterner sitoredüksiyon 2010 yılında bir çalışmada belirtilmiş olup, jinekolojik onkoloji için oldukça yeni bir terminolojidir. $\mathrm{Bu}$ çalışma tersiyer sitoredüksiyon yapılan hastaların devamı şeklinde memorail SloanKetterring kanser merkezindeki 15 hasta değerlendirilmiștir (10). Tüm hastaların daha önceki sekonder ve tersiyer cerrahileri optimaldi. 15 hastanın 10 tanesinde maksimum kuarterner sitoredüksiyon sağlandı.takipte 7 hasta kansere bağlı hayatını kaybetti. Univariant analizlede rezidü tümör dokusu $(<1 \mathrm{~cm} \quad$ ve $>1 \mathrm{~cm})$ ve rekürrens sayısı (tek rekürrens,çok rekürrens) prognostik olarak anlamlı bulunmuştur.

Fanfani ve arkadaşları 53 hastalık bir çalışmayı sunmuşlardır. Cerrahi sırasında diffüz ve izole hastalık oranını \%90,6(48 olgu), ve $5(\% 9,4)$ olarak bulmuşlardır.41 olguya komplet TSS rezeksiyon,1 olguya da optimal rezeksiyon uygulamışlardır. Tümör rezidüsüne 
göre aralarında total săg kalımda istatistiksel olarak anlam çıkmadı. Hastalıksız sağ kalım 2. ve 3 nüks arasında $>12$ ay ise TSS sonras1 hastalıksız sağ kalım 38 ay, <12 ayın altındaki hastalıksız sağ kalımda 7 ay olarak bulunmuştur. Daha sonra 3.kez nüks eden 18 hastanın 12 sine komplet kuarterner cerrahi uygulanmış, 6'sına kemoterapi verilmiştir. KS uygulan hastalarda sırası ile genel sağ kalım 152 ay, kemoterapi verilenlerde 116 ay, hastalısız sağ kalım ise KS cerrahi yapılanlarda 21 ay, kemoterapi alanlarda 16 ay olarak bulunmuştur. Yazar hastalıksız sağ kalımın>12ay olmas1 ve tek bir yerde metastaz olmasinın komplet sitoredaksiyon yapılmasında etkili olduğunu vurgulamışlardır. Fotopoulou ve arkadaşları kuarterner sitoredüksiyon uyguladıkları 49 hastayı incelemişlerdir. Bu hastalardan 8'ine $(\% 16,3)$ dördüncü relapsta, 4'üne $(\% 8,2)$ ise beşinci relapsta kuarterner sitoredüksiyon uygulanmıştır. Toplamda, hastaların \%70'ine over kanseri tanısi aldıktan sonraki 3. İle 10. yıllar arasında kuarterner cerrahi uygulanmıştır ve cerrahi öncesindeki kemoterapiden itibaren geçen median süre 16 aydır. Hastaları 44'ü $(\% 89,9)$ birinci basamak platin bazl kemoterapi almıştır. Hastaların 31'i(\%63,3) platin sensitiftir. Sadece 13 hasta $(\% 26,5)$ platin bazlı kemoterapiyi, kuarterner cerrahi öncesinde 3 . veya 4 . basamak kemoterapi olarak almıştır.

Hastaların büyük çoğunluğu $(\% 67,3)$ FIGO evre 3'tür. Hasların \%90'inda fazlasında asit hiç yok veya $500 \mathrm{cc}$ altında mevcutken, 38 hastada $(\% 77,6)$ kuarterner cerrahi sirasinda peritoneal karsinomatozis saptanmıştır. Sadece 4 hasta (\%8) barsak obstrüksiyonu veya perforasyonu nedeniyle acil ameliyata alınmışken; geriye kalan 45 hasta (\%92) elektif koşullarda ameliyat edilmiştir. Hastaların \%32,6'sinda total makroskopik tümör rezeksiyonu uygulanabilmiştir. Hastaların \%80'inden çoğunda orta veya alt batında tümör mevcuttur. Tüm hastalarda ortalama progresyonsuz sağkalım 22,5 aydır. Total makroskopik rezeksiyonun başarıldığ $1 \% 32,6$ oranındaki hasta popülasyonundaki ortalama genel sağkalım 23.05 ay; median genel sağkalım ise 10 aydır. Hastalar postoperatif rezidü tümör yüküne göre ayrıldığında; total makroskopik rezeksiyon yapılan grupta ortalama genel sağkalım 43 ay; rezidü tümörü olan hastalarda ise 13,4 ay olup, makroskopik rezeksiyon grupta belirgin sağkalım avantaj1 saptanmıştır. Postoperatif adjuvan tedavi alan hastalarda ortalama genel sağkalım; kemoterapi almayanlara göre önemli derecede artmıştır (40.5 aya karşın 12.03 ay). Araştırmacılar kuarterner cerrahide makroskopik tümör rezeksiyonunun sistemik kemoterapi ile kombinasyonunun üçüncü veya daha fazla sayıda relaps görülen epitelyal over kanserleri hastalarında sağkalımı önemli ölçüde arttırdığını saptamıştır. Ayrıca bu çalışmada, hastaların neredeyse yarısında üst abdominal tutulum, üçte ikisinden çoğunda ise peritoneal karsionmatozis bulunmasina rağmen; \%60 '1ndan çoğunda optimal sitoredüksiyon başarılmıştır. $\mathrm{Bu}$ durum, bu cerrahinin, cerrahi açıdan deneyimli ve altyapıs1 yeterli olan merkezlerde yapılmasının önemini vurgulamaktadır. İlginç bu çalışmada peritoneal karsinomatozis, ekstrapelvik tümör yayılımı ve platin direnci gibi iyi bilinen prognostik faktörler, kuarterner cerrahide önemini kaybetmiştir. Ek olarak, bu çalışmada, üçüncü. relapsta veya üçten daha fazla sayıdakide relapsta cerrahi uygulanan hastlarla karşılaştırıldığında sağkalım fark1 bulunmamıştır. Günümüzde sekonder sitoredüksiyon için neredeyse kontrendikasyon olarak kabul edilen "platin direnci"nin, kuarterner cerrahide herhangi bir rolü olmadığ 1 belirlenmiştir ve bunun da cerrahi adaylarının özenle seçilmesi ile ilişkili olduğu yorumu yapılmıştır (21).Yaş, yüksek grade evre gibi faktörler sağ kalımda anlamlı prognostik kriter olarak bulunmamıştır.

\section{SONUÇ}

Rekkürren over kanserli hastalarda bugün için rezidü tümör dokusu bırakmayacak şekilde bir cerrahi yapıldığı takdirde ciddi yaşam avantajı elde edildiğini mevcut çalışmalar göstermektedir. Burada en önemli nokta nüks over kanserli hastaların cerrahi tedavi için doğru seçimidir. Yapılan çalışmalar bu seçimde hastalıksız sağkalım sürelerini, tümör lokalizasyonlarını ve platin bazlı kemoterapiye olan cevabı ön plana çıkmaktadır. Sekonder sitoredüksiyonla ilgili çalışma sayısı fazla olup bu konuda önemli bir düzeye ulaşmıştır. Artık bu hastalarda rezidü hastalık birakmayacak şekilde etkin bir cerrahi uygulanması gerektiği aşikardır. Tersiyer sitoredüksiyonda da yapılan 10-15 arasındaki çalışmalarda da komplet cerrahiye vurgu yapılmaktadır. Kaurterner 
sitoredüksiyonla ilgili çalışmalar sınırlı sayıdadır. Olanlarda da yine rezidü tümör birakmayacak bir cerrahi plana vurgu yapılmaktadır. Tersiyer ve kuarternerle ilgili

\section{REFERANSLAR}

1. Eisenkop SM, Friedman RL, Wang HJ. Complete cytoreductive surgery is feasible and maximizes survival in patients with advanced epithelial ovarian cancer: a prospective study. Gynecol Oncol 1998 May;69(2):103-8.

2. Ozols RF. Recurrent ovarian cancer: evidence-based treatment. J Clin Oncol 2002 Mar 1;20(5):1161-3.

3. Berek JS, Hacker NF, Lagasse LD, Nieberg RK, Elashoff RM. Survival of patients following secondary cytoreductive surgery in ovarian cancer. Obstetrics and gynecology $1983 \mathrm{Feb}$;61(2):189-93.

4. Chi DS, McCaughty K, Diaz JP, Huh J, Schwabenbauer S, Hummer AJ, et al. Guidelines and selection criteria for secondary cytoreductive surgery in patients with recurrent, platinum-sensitive epithelial ovarian carcinoma. Cancer 2006 May 1;106(9):1933-9.

5. Harter $\mathrm{P}, \mathrm{du}$ Bois $\mathrm{A}$, Hahmann $\mathrm{M}$, Hasenburg A, Burges A, Loibl S, et al. Surgery in recurrent ovarian cancer: the Arbeitsgemeinschaft Gynaekologische Onkologie (AGO) DESKTOP OVAR trial. Annals of surgical oncology 2006 Dec;13(12):1702-10.

6. Tian WJ, Jiang R, Cheng X, Tang J, Xing Y, Zang RY. Surgery in recurrent epithelial ovarian cancer: benefits on Survival for patients with residual disease of $0.1-1 \mathrm{~cm}$ after secondary cytoreduction. Journal of surgical oncology 2010 Mar 1;101(3):244-50.

7. Oksefjell H, Sandstad B, Trope C. The role of secondary cytoreduction in the management of the first relapse in epithelial ovarian cancer. Annals of oncology : official journal of the European Society for Medical Oncology / ESMO 2009 Feb;20(2):28693.

8. Gultekin M, Velipasaoglu M, Aksan G, Dursun P, Dogan NU, Yuce K, et al. A third evaluation of tertiary cytoreduction. J Surg Oncol 2008 Dec 1;98(7):530-4.

9. Shih KK, Chi DS, Barakat RR, Leitao MM, Jr. Beyond tertiary cytoreduction in patients with recurrent epithelial ovarian, fallopian tube, or primary peritoneal cancer. Gynecol Oncol 2010 Mar;116(3):364-9.

10. Shih KK, Chi DS, Barakat RR, Leitao MM, Jr. Tertiary cytoreduction in patients with recurrent epithelial ovarian, fallopian tube, or primary peritoneal cancer: an updated series. Gynecol Oncol 2010 May;117(2):330-5.

11. Fotopoulou $C$, Richter $R$, Braicu IE, Schmidt SC, Neuhaus P, Lichtenegger W, et al. Clinical outcome gerek prospektif gerekse retrospektif çalışma sayısının artırılarak bu konudaki bilgi düzeyi artırılmalıdır.

of tertiary surgical cytoreduction in patients with recurrent epithelial ovarian cancer. Ann Surg Oncol 2011 Jan;18(1):49-57.

12. Hizli D, Boran N, Yilmaz S, Turan T, Altinbas SK, Celik B, et al. Best predictors of survival outcome after tertiary cytoreduction in patients with recurrent platinum-sensitive epithelial ovarian cancer. Eur J Obstet Gynecol Reprod Biol 2012 Jul;163(1):71-5.

13. Tang J, Liu DL, Shu S, Tian WJ, Liu Y, Zang RY. Outcomes and patterns of secondary relapse in platinum-sensitive ovarian cancer: implications for tertiary cytoreductive surgery. Eur J Surg Oncol $2013 \mathrm{Jul} ; 39(7): 786-91$.

14. Dogan NU, Schneider A, Chiantera V, Dogan S, Dursun P. Tertiary cytoreduction in the setting of recurrent ovarian cancer (Review). Oncol Lett 2013 Sep;6(3):642-7.

15. Fanfani F, Fagotti A, Ercoli A, Gallotta V, Chiantera $\mathrm{V}$, Restaino S, et al. Is There a Role for Tertiary (TCR) and Quaternary (QCR) Cytoreduction in Recurrent Ovarian Cancer? Anticancer research 2015 Dec;35(12):6951-5.

16. Karam AK, Santillan A, Bristow RE, Giuntoli R, 2nd, Gardner GJ, Cass I, et al. Tertiary cytoreductive surgery in recurrent ovarian cancer: selection criteria and survival outcome. Gynecologic oncology 2007 Feb;104(2):377-80

17. Arvas M, Salihoglu Y, Sal V, Gungor T, Sozen H, Kahramanoglu I, et al. Tertiary Cytoreduction for Recurrent Epithelial Ovarian Cancer: a Multicenter Study in Turkey. Asian Pacific journal of cancer prevention : APJCP 2016;17(4):1909-15.

18. Kusumoto S, Konishi H, Okame S, Komatsu M, Shiroyama Y, Yokoyama T, et al. [Outcomes of Tertiary Debulking Surgery(TDS)for Re-Recurrent Ovarian Cancer]. Gan to kagaku ryoho Cancer \& chemotherapy 2016 Mar;43(3):357-60.

19. Fotopoulou C, Zang R, Gultekin M, Cibula D, Ayhan A, Liu D, et al. Value of tertiary cytoreductive surgery in epithelial ovarian cancer: an international multicenter evaluation. Annals of surgical oncology 2013 Apr;20(4):1348-54.

20. Leitao MM, Jr., Kardos S, Barakat RR, Chi DS. Tertiary cytoreduction in patients with recurrent ovarian carcinoma. Gynecologic oncology 2004 Oct;95(1):181-8.

21. Fotopoulou C, Savvatis K, Kosian P, Braicu IE, Papanikolaou G, Pietzner K, et al. Quaternary cytoreductive surgery in ovarian cancer: does surgical effort still matter? British journal of cancer 2013 Jan 15;108(1):32-8. 